\title{
The association between BIS/BAS and fear of COVID-19 infection among women
}

\author{
Włodzimierz Oniszczenko (D) \\ Faculty of Psychology, University of Warsaw, Warsaw, Poland
}

\section{BACKGROUND}

The main goal of this cross-sectional study was to evaluate, in women, the association between the behavioural inhibition system/behavioural activation system (BIS/BAS) and fear of COVID-19-related self-infection and infection of loved ones (family members, friends, relatives). Several studies have indicated that the psychological consequences of COVID-19 are serious especially among women. On the other hand, little is known about the role of the BIS and BAS in shaping responses and behaviour during the COVID-19 pandemic. The article deals with this issue.

\section{PARTICIPANTS AND PROCEDURE}

The sample consisted of 415 women between the ages of 18 and 67 . A numerical rating scale comprising 11 degrees of fear was used to assess participants' COVID-19-related fear, and the BIS and BAS were evaluated using Carver and White's BIS/BAS scales.

\section{RESULTS}

A small positive correlation was observed between the BIS and participants' COVID-19-related fear of loved ones' infection. The BIS explained two percent of the COVID-19related fear of loved ones' infection dimension.

\section{CONCLUSIONS}

The BIS weakly, but significantly correlated with women's fear of their loved ones being infected by COVID-19. This study highlights the possible role of the BIS mechanism in women's response to COVID-19-related fear, but only when the threat affects loved ones. Comparative studies between men and women are necessary.

\section{KEY WORDS}

adults; women; COVID-19-related fear; BIS/BAS

Corresponding author - Prof. Włodzimierz Oniszczenko, Faculty of Psychology, University of Warsaw, 5-7 Stawki Str., 00-183 Warsaw, Poland, e-mail: wlodek@psych.uw.edu.pl

AUthors' CONTRIBUtion - A: Study design - B: Data collection - C: Statistical analysis - D: Data interpretation .

E: Manuscript preparation · F: Literature search · G: Funds collection

TO CITE THIS ARTICLE - Oniszczenko, W. (2021). The association between BIS/BAS and fear of COVID-19 infection

among women. Current Issues in Personality Psychology, 9(3), 237-245.

RECEIVED 23.10.2020 • REVIEWED 10.03.2021 · ACCEPTED 12.04.2021 · PUBLISHED 17.05.2021 


\section{BACKGROUND}

COVID-19 is an infectious disease that causes mild to moderate symptoms of respiratory distress and occasionally severe symptoms - up to and including death. In addition to somatic symptoms, COVID-19 is associated with many burdensome restrictions on people's social sphere, including the maintenance of social distance and isolation (Adhikari et al., 2020). Several studies have indicated that the psychological consequences of the COVID-19 pandemic are equally serious. For example, higher levels of anxiety and depression were typically displayed in health professionals (da Silva \& Neto, 2021) and in the general Italian population - one of those most affected by COVID-19 (Mazza et al., 2020). Moreover, PTSD symptoms, depression, extreme anxiety, and sleep disorders were shown to be the most significant risk factors for Chinese students in quarantine developing mental health problems (Tang et al., 2020).

Several studies have indicated that the COVID-19 pandemic was more of a challenge for women than for men. According to Galasso et al. (2020), more women than men in America and Europe considered the COVID-19 pandemic a significant threat, primarily for themselves. Furthermore, Zamarro and Prados (2021) demonstrated that women were heavily burdened with caring for young children, even when they were working, and they experienced severe psychological distress associated with the risk of losing a job.

Many studies pointed out differences between men and women in response to the COVID-19 threat. In a study of Chinese health care workers, gender was demonstrably one of the most significant risk factors for anxiety, along with contact history and one's access to protective measures. Symptoms of anxiety and depression were observed significantly more often in women than in men (Fitzpatrick et al., 2020; Rodríguez-Rey et al., 2020; Xiao et al., 2020). According to García-Fernández et al. (2021), women exhibited higher acute stress levels in response to the development of the COVID-19 pandemic compared to men. Similarly, Hou et al. (2020) found severe stress and worse resilience to stress in women than in men. Moreover, Liu et al. (2020) highlighted the presence of significantly higher levels of posttraumatic stress symptoms, such as re-experiencing or hyper-arousal, in women compared to men. Mazza et al. (2020) showed that individuals, especially women, who had an infected family member or acquaintance reacted with a higher level of anxiety and depression. Furthermore, fear for oneself and beloved others may be reduced by high levels of optimism, general trust, and a lack of belief in conspiracy theories (Jovančević \& Milićević, 2020). In Hungary, it has been shown that young people with an average or below average perceived health condition, as well as women, faced the most stress in reaction to the early stage of COVID-19. Hungarian women were more worried about the virus but also agreed more with the government's interventions (Szabo et al., 2020; see also Alonzi et al., 2020). De Coninck et al. (2020) also suggested that elderly people and women perceive themselves as more susceptible to COVID-19 infection. Finally, maladaptive coping mechanisms among people who are more prone to stress (e.g., the elderly, those with chronic diseases, or pregnant women) indicate a lower tolerance to uncertainty caused by the COVID-19 pandemic and, thus, a greater frequency of anxiety and depression (Rettie \& Daniels, 2020).

Knowledge about the links between personality and psychological reaction to the COVID-19 pandemic is still in the initial stages. For example, negative affectivity, detachment, antagonism, and psychoticism were related to psychometrically measured emotional problems in Italians during the first month of the COVID-19 pandemic (Somma et al., 2020). Aschwanden et al. (2020) found that higher levels of neuroticism were associated with longer COVID-19 pandemic duration estimates, whereas higher levels of extraversion were related to shorter pandemic duration estimates. Fernández et al. (2020) corroborated this, reporting that women with high levels of neuroticism and COVID-19-related fear faced greater psychological distress under quarantine conditions. Moccia et al. (2020) further demonstrated that high levels of psychological distress perceived in the general Italian population during an early stage of the pandemic were associated with high levels of depressive, cyclothymic, and anxious affective temperaments. Prentice et al. (2020) also suggested that emotional intelligence may positively impact proactive coping strategies in a pandemic situation.

The BIS and BAS theories offer some of the most accurate descriptions of the relationship between personality and psychopathology (Bijttebier et al., 2009; Kimbrel et al., 2007). However, little is known about the role of BIS/BAS mechanisms in behaviour regulation under the threatening conditions of COVID-19.

According to the original version of Gray's (1982) reinforcement sensitivity theory (RST), personality includes two basic, separate brain-motivational systems detecting and responding to appetitive or aversive signals: the behavioural inhibition system (BIS) and the behavioural activation system (BAS). The original RST suggests that the BAS is activated by conditioned appetite stimuli (e.g., reward stimuli). According to Carver and White (1994), BAS is associated with the search for anticipated rewards (BAS Reward Responsiveness), the achievement of goals (BAS Drive), and the desire for new stimuli (BAS Fun Seeking). 
On the other hand, BIS is associated with sensitivity to conditional aversive stimuli (e.g., punishment signals; Gray, 1982). Behavioural inhibition system activity is responsible for the experience of negative feelings such as fear, anxiety, frustration, or sadness in response to signals of punishment, a lack of reward, or novelty (Gray, 1990). According to Gray (1994), the BIS regulates arousal and attention when an individual encounters punishment signals and novel and fear-related stimuli. It seems that, for many people, the COVID-19 pandemic developments are new, unknown, and fear-related stimuli. As a result, in these people, a strong BIS may produce not only anxiety, but other symptoms as well, such as depression and social dysfunction. Katz et al. (2020) confirmed that high BIS sensitivity is related to depression and anxiety. Moreover, Katz and Yovel (2020) demonstrated the relationship between punishment sensitivity and rumination, a mechanism that linked stressful life situations (e.g., a pandemic situation) with depression and anxiety (Michl et al., 2013). Heponiemi et al. (2003) further demonstrated that BIS sensitivity could predispose a person to emotional distress and may generally increase his or her susceptibility to stress in various situations. Kennis et al. (2013) suggested that BIS activation is associated with neuroticism and anxiety traits, whereas BAS activation is associated with extraversion, novelty seeking, reward dependence, and openness to experience. Such connections indicate the potential role of BIS and BAS in the regulation of behaviour in stressful situations.

\section{CURRENT STUDY}

The results of numerous studies have consistently shown that the COVID-19 pandemic has presented a greater burden for women than for men. Moreover, compared to men, women react with greater stress to the COVID-19 threat. Risks arising from COVID-19 may apply directly to the entity or his or her loved ones, such as family members, friends, or relatives. We thought it interesting to explore to what extent women experience fear of self-infection and to what extent fear of loved ones' infection. Moreover, we were interested in the role of BIS/BAS mechanisms in this process. As Ma-Kellams and Wu (2020) demonstrated, high BIS levels observed in women compared to men, at a comparable BAS level, could explain women's reactions such as sadness or fear in response to negative experiences (e.g., natural disasters). This study investigated the relationship between the BIS and fear of COVID-19-related selfinfection and loved ones' infection among women. High BIS levels were hypothesized to show a positive association with both of the aforementioned fears.

\section{PARTICIPANTS AND PROCEDURE}

\section{PARTICIPANTS}

The study sample comprised 415 women gathered from the general population via the University of Warsaw online recruitment platform. The participants' ages ranged from 18 to 67 years $(M=30.20$, $S D=9.60)$. Table 1 presents the sociodemographic characteristics of the study sample.

\section{PROCEDURE}

This was an anonymous study, and participation was voluntary and without compensation. Each participant provided informed consent at the beginning of the questionnaire. Data were collected between April 2020 and May 2020 during a high-intensity period of coronavirus infections in Poland. All procedures performed in the studies were approved by the local Research Ethics Commission at the University of Warsaw, Faculty of Psychology.

\section{MEASUREMENTS}

An 11-point numerical rating scale was used to measure the intensity of fear of COVID-19 infection for oneself and loved ones (family members, friends, relatives). Each participant assessed the severity of fear they experienced at the time of testing by point-

\section{Table 1}

Sociodemographic variables in the studied sample $(N=415)$

\begin{tabular}{lc}
\hline Variables & Women \\
\hline Education, $n(\%)$ & $277(66.7)$ \\
Higher & $132(31.8)$ \\
Secondary & $6(1.4)$ \\
Primary & \\
Marital status, $n(\%)$ & $183(44.1)$ \\
$\quad$ Single & $204(49.2)$ \\
Married & $28(6.7)$ \\
Divorced & \\
Place of residence, $n(\%)$ & $82(19.8)$ \\
$\quad$ Rural areas & $54(13.0)$ \\
Small towns & $279(67.2)$ \\
$\quad$ Large cities
\end{tabular}


ing to a number on a scale from 0 (I feel absolutely no fear) to 10 (I feel unimaginable fear). A higher total score on this scale thus indicated greater fear. The same scale was used for the COVID-19 fear assessment in the US regions (Fitzpatrick et al., 2020), as well as for the threat of coronavirus infection assessment among cancer patients during therapy in a Polish population (Sigorski et al., 2020). It is worth noting that 11-point numerical scales are also used for pain intensity diagnosis (Farrar et al., 2001), for measuring pain and tiredness among cancer patients (Oldenmenger et al., 2013), and to describe the stress experienced by adolescents and adults (Karvounides et al., 2016).

Participants' BIS and BAS were assessed using Müller and Wytykowska's (2005) Polish version of the BIS/BAS scales (Carver \& White, 1994). The BIS/ BAS scales consisted of a 20-item questionnaire with four scales (Cronbach's $\alpha$ coefficients for the current sample are in parentheses): BIS ( $\alpha=.87$; Criticism or scolding hurts me quite a bit), BAS Drive ( $\alpha=.70$; I go out of my way to get things I want), BAS Fun Seeking ( $\alpha=.63 ;$ I crave excitement and new sensations), and BAS Reward Responsiveness ( $\alpha=.77$; It would excite me to win a contest).

\section{STATISTICAL ANALYSIS}

All computations were done using IBM's (2017) SPSS Statistics 25 statistical package. All questionnaire data were digitally recorded. Relationships among variables were examined with Pearson product-moment coefficients (an absolute value of $r=.1$ is classified as small, an absolute value of $r=.3$ is classified as medium, and an absolute value of $r=.5$ is classified as large; Cohen, 1988).

\section{RESULTS}

Data normality was checked based on the skewness and kurtosis values (ranged from -1.5 to 1.5 ) following the criteria specified by Tabachnick and Fidell (2013).

All the data analysed in the study reached the criterion of compliance with the normal distribution.

Table 2 provides the descriptive statistics and the Pearson's $r$ correlations for the sample. A low positive correlation was observed between participants' BIS and fear of loved ones' COVID-19 infection. The female group displayed significantly greater fear of loved ones contracting COVID-19 compared to their fear of self-infection $(t=-18.73, d f=414, p<.001$, Cohen's $d=.82$ ).

To determine the extent to which BIS and BAS can be viewed as predictors of COVID-19-related fears, a linear regression analysis was conducted. An analysis of the variance inflation factors (VIFs) suggested no multicollinearity between predictors in the regression analysis (all VIFs $<2$, tolerances $>.50$ ). Based on the regression coefficients, the BIS $(\beta=.16$, $p<.01)$ proved to be a significant predictor of a fear of loved ones being infected by COVID-19. The results are summarized in Table 3 .

\section{DISCUSSION}

The present study found a relationship between high BIS sensitivity and fear of loved ones' infection with COVID-19 among women, although this effect was weak. For biological and socio-cultural reasons (McLean \& Anderson, 2009), women are generally more prone to fear than men, but these differences may also be based on the regulative role of the BIS. According to Leen-Feldner et al. (2004), people

\section{Table 2}

Descriptive statistics and Pearson's r correlations between BIS and BAS scales and COVID-19-related fear of self-infection (SI) or loved ones' infection (LOI) in the sample $(N=415)$

\begin{tabular}{lrrrrrr}
\hline & Women & BAS D & BAS FS & BAS RR & COVID-19 & COVID-19 \\
& $M(S D)$ & & & & SI & LOI \\
\hline BIS & $21.06(5.19)$ & $-.13^{* *}$ & -.01 & $.51^{* * *}$ & .09 & $.16^{* * *}$ \\
BAS Drive (BAS D) & $9.87(2.60)$ & & $.38^{* * *}$ & $.33^{* * *}$ & -.02 & -.03 \\
BAS Fun Seeking (BAS FS) & $10.57(2.64)$ & & $.40^{* * *}$ & -.06 & -.02 \\
BAS Reward Responsiveness & $15.35(3.51)$ & & & .05 & .08 \\
(BAS RR) & & & & & $.61^{* * *}$ \\
COVID-19 self-infection fear (SI) & $4.07(2.38)$ & & & & & - \\
COVID-19 fear of loved ones' & $6.23(2.87)$ & & & & & \\
infection (LOI) & & & & & & \\
\hline
\end{tabular}

Note. BIS - behavioural inhibition system; BAS - behavioural activation system; ${ }^{* *} p<.01,{ }^{* * *} p<.001$. 
Table 3

Linear regression analysis of BIS/BAS dimensions as predictors of COVID-19-related fear of self-infection (SI) and loved ones' infection (LOI) in the whole sample $(N=415)$ with variance inflation factor (VIF)

\begin{tabular}{|c|c|c|c|c|c|c|c|}
\hline Variables & B & SE & $\beta$ & $R^{2}$ adjusted & $\begin{array}{l}\text { Semi-partial } \\
\text { correlations }\end{array}$ & VIF & Tolerance \\
\hline COVID-19 SI & & & & .00 & & & \\
\hline BIS & .03 & .03 & .07 & & .05 & 1.61 & .62 \\
\hline BAS D & .00 & .05 & .00 & & .00 & 1.36 & .74 \\
\hline BAS FS & -.08 & .05 & -.09 & & -.08 & 1.35 & .74 \\
\hline BAS RR & .04 & .05 & .05 & & .04 & 1.97 & .51 \\
\hline COVID-19 LOI & & & & .02 & & & \\
\hline BIS & .09 & .03 & $.16^{* *}$ & & .13 & 1.61 & .62 \\
\hline BAS D & .00 & .06 & .00 & & .00 & 1.36 & .74 \\
\hline BAS FS & -.03 & .06 & -.03 & & -.02 & 1.35 & .74 \\
\hline BAS RR & .01 & .06 & .01 & & .00 & 1.97 & .51 \\
\hline
\end{tabular}

who encounter new fear-related stimuli (which the COVID-19 pandemic has generated) respond with stronger arousal upon activation of the BIS. In general, women have perceived high levels of stress in reaction to COVID-19 and its consequences (Ausín et al., 2020; Broche-Pérez et al., 2020; di Fronso et al., 2020; Fitzpatrick et al., 2020; Szabo et al., 2020). As López-Atanes et al. (2020) suggested, the greater severity of psychological distress among women in response to COVID-19 may be attributed to tensions such as economic inequalities, insufficient recognition, greater involvement in housework, and increased childcare. In the case of health care workers, female staff comprise the majority of those who directly care for COVID patients - a potentially fatal occupational hazard.

The stimulation of the BIS is associated with passive avoidance, leading to the assessment of the risk associated with the event, rumination, and consequent anxiety (Merchán-Clavellino et al., 2019). The current COVID-19 pandemic has significantly increased uncertainty about the economy, employment, finances, relationships, and physical and mental health. We believe that women who have higher BIS levels are more likely to exhibit fear of COVID-19 infection under such conditions, and rumination may intensify this process. Women may not tolerate uncertainty as well as men (Doruk et al., 2015), and this intolerance "reflects a core component of anxiety", perhaps even "the most fundamental fear" (Ouellet et al., 2019, p. 10).

Our results indicate that women have a much greater fear of their loved ones becoming infected with COVID-19 compared to their fear of self-infection. This suggests that women are more oriented towards the risk of COVID-19 infection in their relatives (family members, friends, or relatives) than themselves. This may be a result of the traditionally defined role of a woman - shaped by social expectations and gender norms - as a person performing caring functions within a family (see Ketcher et al., 2020).

According to Power (2020), women had already performed unpaid care work prior to the COVID-19 pandemic, but the pandemic crisis and related lockdown caused this burden to rise dramatically. Rodrigues et al. (2021) stressed that, during the COVID-19 pandemic, women most often took care of the elderly, sometimes living outside the household, and more often took on other tasks such as childcare or housework. In his review, Connnor et al. (2020) drew attention to women working in health care and taking care of patients. According to the authors of the review, social norms that require women to assume caring roles in hospitals are particularly strengthened during a pandemic. It cannot be ruled out that women's attitudes towards caring for family members may increase their concerns about the infection of COVID-19 in other relatives as well and may increase their fear of loved ones being infected by COVID- 19 .

Our results partially confirmed the hypothesis regarding the association between the BIS and women's fear responses related to COVID-19 infection. Analysis of the results showed that the BIS explained only $2 \%$ of the variance in the fear of COVID-19 in- 
fection in loved ones. Despite such a low score, it notably points to the possible significance of the BIS for the level of fear of COVID-19. Certainly, the BIS is not the only factor explaining the level of fear studied. It is likely that other personality traits, such as anxiety as a trait, neuroticism, or harm avoidance, are also important for the fear level tested.

Nevertheless, our study is not without limitations. Notably, only a group of women was studied, and extending it to include men may affect the final study result. The exclusively female sample may have limited our ability to generalise the results. The fact that we studied well-educated women living in cities could also have been significant for the level of recorded variables. We suggest including men and more diverse participants in terms of education and place of residence in future research. Moreover, we did not document the presence of physical and mental health disorders in the participants, nor did we observe how their social situation could affect their emotional state during the pandemic. We also did not control for other personality variables that could affect their level of COVID-19-related fear. Furthermore, the cross-sectional study design limited the understanding of causal processes between the BIS and COVID-19 fears. The final limitation resulted from the use of Carver and White's BIS/BAS scales in the present research. This measure was based on Gray's original reinforcement sensitivity theory (RST), rather than the more recent revision of the theory. Although research indicates a similarity between Carver's and revised measures of BIS/BAS, we suggest future comparative studies including both the original BIS/BAS measure and the revised RST measure.

\section{CONCLUSIONS}

The BIS weakly, but significantly correlated with women's fear of their loved ones being infected by COVID-19. This study highlights the role of the BIS mechanism in women's response to COVID-19-related fear, but only when the threat affects loved ones. Comparative studies between men and women are necessary.

\section{ACKNOWLEDGEMENTS}

This work was supported by the University of Warsaw, Faculty of Psychology via funds awarded by the Ministry of Science and Higher Education in the form of a subsidy for the maintenance and development of research potential in 2021 No. 501-D125-01-1250000. This research did not receive any specific grants from funding agencies in the public, commercial, or notfor-profit sectors.

\section{References}

Adhikari, S. P., Meng, S., Wu, Y. J., Mao, Y. P., Ye, R. X., Wang, Q. Z., Sun, C., Sylvia, S., Rozelle, S., Raat, H., \& Zhou, H. (2020). Epidemiology, causes, clinical manifestation and diagnosis, prevention and control of coronavirus disease (COVID-19) during the early outbreak period: a scoping review. Infectious Diseases of Poverty, 9, 29. https://doi.org/10.1186/ s40249-020-00646-x

Alonzi, S., La Torre, A., \& Silverstein, M. W. (2020). The psychological impact of pre-existing mental and physical health conditions during the COVID-19 pandemic. Psychological Trauma: Theory, Research, Practice, and Policy, 12, S236-S238. https://doi.org/ 10.1037/tra0000840

Aschwanden, D., Strickhouser, J. E., Sesker, A. A., Lee, J. H., Luchetti, M., Stephan, Y., Sutin, A. R., \& Terracciano, A. (2020). Psychological and behavioural responses to coronavirus disease 2019: The role of personality. European Journal of Personality. https://doi.org/10.1002/per.2281

Ausín, B., González-Sanguino, C., Castellanos, M. Á., \& Muñoz, M. (2020). Gender-related differences in the psychological impact of confinement as a consequence of COVID-19 in Spain. Journal of Gender Studies. https://doi.org/10.1080/09589236.2 020.1799768

Bijttebier, P., Beck, I., Claes, L., \& Vandereycken, W. (2009). Gray's Reinforcement Sensitivity Theory as a framework for research on personalitypsychopathology associations. Clinical Psychology Review, 29, 421-430. https://doi.org/10.1016/j. cpr.2009.04.002

Broche-Pérez, Y., Fernández-Fleites, Z., JiménezPuig, E., Fernández-Castillo, E., \& Rodríguez-Martin, B. C. (2020). Gender and fear of COVID-19 in a Cuban population sample. International Journal of Mental Health and Addiction. https://doi. org/10.1007/s11469-020-00343-8

Carver, C. S., \& White, T. L. (1994). Behavioral inhibition, behavioral activation, and affective responses to impending reward and punishment: The BIS/ BAS scales. Journal of Personality and Social Psychology, 67, 319-333. https://doi.org/10.1037/00223514.67.2.31

Cohen, J. (1988). Statistical power analysis for the behavioral sciences (2nd ed.). Erlbaum.

Connor, J., Madhavan, S., Mokashi, M., Amanuel, H., Johnson, N. R., Pace, L. E., \& Bartz, D. (2020). Health risks and outcomes that disproportionately affect women during the Covid-19 pandemic: a review. Social Science \& Medicine, 266, 113364. https://doi.org/10.1016/j.socscimed.2020.113364

da Silva, F. C. T., \& Neto, M. L. R. (2021). Psychological effects caused by the COVID-19 pandemic in health professionals: a systematic review with meta-analysis. Progress in Neuro-Psychopharmacology 
and Biological Psychiatry, 104, 110062. https://doi. org/10.1016/j.pnpbp.2020.110062

De Coninck, D., d'Haenens, L., \& Matthijs, K. (2020). Perceived vulnerability to disease and attitudes towards public health measures: COVID-19 in Flanders, Belgium. Personality and Individual Differences, 166, 110220. https://doi.org/10.1016/j.paid. 2020.110220

di Fronso, S., Costa, S., Montesano, C., Di Gruttola, F., Ciofi, E. G., Morgilli, L., Robazza, C., \& Bertollo, M. (2020). The effects of COVID-19 pandemic on perceived stress and psychobiosocial states in Italian athletes. International Journal of Sport and Exercise Psychology. https://doi.org/10.1080/ 1612197X.2020.1802612

Doruk, A., Dugenci, M., Ersöz, F., \& Öznur, T. (2015). Intolerance of uncertainty and coping mechanisms in nonclinical young subjects. Archives of $\mathrm{Neu}^{-}$ ropsychiatry, 52, 400-405. https://doi.org/10.5152/ npa.2015.8779

Fernández, R. S., Crivelli, L., Guimet, N. M., Allegri, R. F., \& Pedreira, M. E. (2020). Psychological distress associated with COVID-19 quarantine: Latent profile analysis, outcome prediction and mediation analysis. Journal of Affective Disorders, 277, 75-84. https://doi.org/10.1016/j.jad.2020.07.133

Farrar, J. T., Young, J. P., LaMoreaux, L., Werth, J. L., \& Poole, R. (2001). Clinical importance of changes in chronic pain intensity measured on an 11-point numerical pain rating scale. Pain, 94, 149-158. https://doi.org/10.1016/S0304-3959(01)00349-9

Fitzpatrick, K. M., Harris, C., \& Drawve, G. (2020). Fear of COVID-19 and the mental health consequences in America. Psychological Trauma: Theory, Research, Practice, and Policy, 12, S17-S21. https:// doi.org/10.1037/tra0000924

Galasso, V., Pons, V., Profeta, P., Becher, M., Brouard, S., \& Foucault, M. (2020). Gender differences in COVID-19 attitudes and behavior: Panel evidence from eight countries. Proceedings of the National Academy of Sciences of the United States of America, 117, 27285-27291. https://doi.org/10.1073/ pnas. 2012520117

García-Fernández, L., Romero-Ferreiro, V., Padilla, S., David López-Roldán, P., Monzó-García, M., \& Rodriguez-Jimenez, R. (2021). Gender differences in emotional response to the COVID-19 outbreak in Spain. Brain and Behavior, 11, e01934. https://doi. org/10.1002/brb3.1934

Gray, J. A. (1982). The neuropsychology of anxiety: an enquiry into the functions of the septo-hippocampal system of the septo-hippocampal system. Oxford University Press.

Gray, J. A. (1990). Brain systems that mediate both emotion and cognition. Cognition and Emotion, 4, 269-288. https://doi.org/10.1080/02699939008410799

Gray, J. A. (1994). Framework for a taxonomy of psychiatric disorder. In S. H. M. van Goozen, N. E. Van de Poll, \& J. A. Sergeant (Eds.), Emotions: Essays on emotion theory (pp. 29-59). Lawrence Erlbaum Associates.

Heponiemi, T., Keltikangas-Järvinen, L., Puttonen, S., \& Ravaja, N. (2003). BIS/BAS sensitivity and selfrated affects during experimentally induced stress. Personality and Individual Differences, 34, 943-957. https://doi.org/10.1016/S0191-8869(02)00079-X

Hou, F., Bi, F., Jiao, R., Luo, D., \& Song, K. (2020). Gender differences of depression and anxiety among social media users during the COVID-19 outbreak in China: a cross-sectional study. BMC Public Health, 20, 1648. https://doi.org/10.1186/s12889-020-09738-7

IBM Corporation (2017). IBM SPSS Statistics for Windows, Version 25.0.

Jovančević, A., \& Milićević, N. (2020). Optimism-pessimism, conspiracy theories and general trust as factors contributing to COVID-19 related behavior - a cross-cultural study. Personality and Individual Differences, 167, 110216. https://doi.org/10.1016/j. paid.2020.110216

Karvounides, D., Simpson, P. M., Davies, W. H., Khan, K. A., Weisman, S. J., \& Hainsworth, K. R. (2016). Three studies supporting the initial validation of the stress numerical rating scale-11 (Stress NRS-11): a single item measure of momentary stress for adolescents and adults. Pediatric Dimensions, 1, 105-109. https://doi.org/10.15761/pd. 1000124

Katz, B. A., Matanky, K., Aviram, G., \& Yovel, I. (2020). Reinforcement sensitivity, depression and anxiety: a meta-analysis and meta-analytic structural equation model. Clinical Psychology Review, 77, 101842. https://doi.org/10.1016/j.cpr.2020.101842

Katz, B. A., \& Yovel, I. (2020, December 21). A cognitive coping model of reinforcement sensitivity, emotion regulation, and affective psychopathology: Cross-sectional, longitudinal and quasi-experimental evidence. PsyArXiv. https://doi.org/10. 31234/osf.io/wmr25

Kennis, M., Rademaker, A. R., \& Geuze, E. (2013). Neural correlates of personality: an integrative review. Neuroscience and Biobehavioral Reviews, 37, 73-95. https://doi.org/10.1016/j.neubiorev.2012.10.012

Ketcher, D., Trettevik, R., Vadaparampil, S. T., Heyman, R. E., Ellington, L., \& Reblin, M. (2020). Caring for a spouse with advanced cancer: Similarities and differences for male and female caregivers. Journal of Behavioral Medicine, 43, 817-828. https:// doi.org/10.1007/s10865-019-00128-y

Kimbrel, N. A., Nelson-Gray, R. O., \& Mitchell, J. T. (2007). Reinforcement sensitivity and maternal style as predictors of psychopathology. Personality and Individual Differences, 42, 1139-1149. https:// doi.org/10.1016/j.paid.2006.06.028

Leen-Feldner, E. W., Zvolensky, M. J., \& Feldner, M. T. (2004). Behavioral inhibition sensitivity and emotional response suppression: a laboratory test 
among adolescents in a fear-relevant paradigm. Journal of Clinical Child and Adolescent Psychology, 33, 783-791. https://doi.org/10.1207/s15374424jccp3304_13

Liu, N., Zhang, F., Wei, C., Jia, Y., Shang, Z., Sun, L., Wu, L., Sun, Z., Zhou, Y., Wang, Y., \& Liu, W. (2020). Prevalence and predictors of PTSS during COVID-19 outbreak in China hardest-hit areas: Gender differences matter. Psychiatry Research, 287, 112921. https://doi.org/10.1016/j.psychres.2020.112921

López-Atanes, M., Recio-Barbero, M., \& Sáenz-Herrero, M. (2020). Are women still "the other?" Gendered mental health interventions for health care workers in Spain during COVID-19. Psychological Trauma: Theory, Research, Practice, and Policy, 12, S243-S244. https://doi.org/10.1037/tra0000751

Ma-Kellams, C., \& Wu, M. S. (2020). Gender, behavioral inhibition/activation, and emotional reactions to negative natural and social events. Personality and Individual Differences, 157, 109809. https://doi. org/10.1016/j.paid.2019.109809

Mazza, C., Ricci, E., Biondi, S., Colasanti, M., Ferracuti, S., Napoli, C., \& Roma, P. (2020). A nationwide survey of psychological distress among Italian people during the COVID-19 pandemic: Immediate psychological responses and associated factors. International Journal of Environmental Research and Public Health, 17, 3165. https://doi.org/10.3390/ ijerph 17093165

McLean, C. P., \& Anderson, E. R. (2009). Brave men and timid women? A review of the gender differences in fear and anxiety. Clinical Psychology Review, 29, 496-505. https://doi.org/10.1016/j.cpr.2009.05.003

Merchán-Clavellino, A., Alameda-Bailén, J. R., Zayas García., A., \& Guil, R. (2019). Mediating effect of trait emotional intelligence between the behavioral activation system (BAS)/behavioral inhibition system (BIS) and positive and negative affect. Frontiers in Psychology, 10, 424. https://doi. org/10.3389/fpsyg.2019.00424

Michl, L. C., McLaughlin, K. A., Shepherd, K., \& Nolen-Hoeksema, S. (2013). Rumination as a mechanism linking stressful life events to symptoms of depression and anxiety: Longitudinal evidence in early adolescents and adults. Journal of Abnormal Psychology, 122, 339-352. https://doi.org/10.1037/ a0031994

Moccia, L., Janiri, D., Pepe, M., Dattoli, L., Molinaro, M., De Martin, V., Chieffo, D., Janiri, L., Fiorillo, A., Sani, G., \& Di Nicola, M. (2020). Affective temperament, attachment style, and the psychological impact of the COVID-19 outbreak: an early report on the Italian general population. Brain, Behavior, and Immunity, 87, 75-79. https:// doi.org/10.1016/j.bbi.2020.04.048

Müller, J. M., \& Wytykowska, A. M. (2005). Psychometric properties and validation of a Polish adaptation of Carver and White's BIS/BAS scales.
Personality and Individual Differences, 39, 795-805. https://doi.org/10.1016/j.paid.2005.03.006

Oldenmenger, W. H., de Raaf, P. J., de Klerk, C., \& van der Rijt, C. C. (2013). Cut points on 0-10 numeric rating scales for symptoms included in the $\mathrm{Ed}$ monton Symptom Assessment Scale in cancer patients: a systematic review. Journal of Pain and Symptom Management, 45, 1083-1093. https://doi. org/10.1016/j.jpainsymman.2012.06.007

Ouellet, C., Langlois, F., Provencher, M. D., \& Gosselin, P. (2019). Intolerance of uncertainty and difficulties in emotion regulation: Proposal for an integrative model of generalized anxiety disorder. European Review of Applied Psychology, 69, 9-18. https://doi.org/10.1016/j.erap.2019.01.001

Power, K. (2020). The COVID-19 pandemic has increased the care burden of women and families. Sustainability: Science, Practice, and Policy, 16, 6773. https://doi.org/10.1080/15487733.2020.1776561

Prentice, C., Zeidan, S., \& Wang, X. (2020). Personality, trait El and coping with COVID-19 measures. International Journal of Disaster Risk Reduction, 51, 101789. https://doi.org/10.1016/j.ijdrr.2020.101789

Rettie, H., \& Daniels, J. (2020). Coping and tolerance of uncertainty: Predictors and mediators of mental health during the COVID-19 pandemic. American Psychologist. https://doi.org/10.1037/amp0000710

Rodrigues, R., Simmons, C., Schmidt, A. E., \& Steiber, N. (2021). Care in times of COVID-19: The impact of the pandemic on informal caregiving in Austria. European Journal of Ageing. https://doi. org/10.1007/s10433-021-00611-z

Rodríguez-Rey, R., Garrido-Hernansaiz, H., \& Collado, S. (2020). Psychological impact of COVID-19 in Spain: Early data report. Psychological Trauma: Theory, Research, Practice, and Policy, 12, 550-552. https://doi.org/10.1037/tra0000943

Sigorski, D., Sobczuk, P., Osmola, M., Kuć, K., Walerzak, A., Wilk, M., Ciszewski, T., Kopeć, S., Hryń, K., Rutkowski, P., Stec, R., Szczylik, C., \& Bodnar, L. (2020). Impact of COVID-19 on anxiety levels among patients with cancer actively treated with systemic therapy. ESMO Open, 5, e000970. https:// doi.org/10.1136/ esmoopen-2020-000970

Somma, A., Gialdi, G., Krueger R. F., Markon, K. E., Fraud, C., Lovallo, S., \& Fossati, A. (2020). Dysfunctional personality features, non-scientifically supported causal beliefs, and emotional problems during the first month of the COVID-19 pandemic in Italy. Personality and Individual Differences, 165, 110139. https://doi.org/10.1016/j.paid.2020.110139

Szabo, A., Ábel, K., \& Boros, S. (2020). Attitudes toward COVID-19 and stress levels in Hungary: Effects of age, perceived health status, and gender. Psychological Trauma: Theory, Research, Practice, and Policy, 12, 572-575. https://doi.org/10.1037/tra0000665

Tabachnick, B. G., \& Fidell, L. S. (2013). Using multivariate statistics (6th edition). Pearson. 
Tang, W., Hu, T., Hu, B., Jin, C., Wang, G., Xie, C., Chen, S., \& Xu, J. (2020). Prevalence and correlates of PTSD and depressive symptoms one month after the outbreak of the COVID-19 epidemic in a sample of home-quarantined Chinese university students. Journal of Affective Disorders, 274, 1-7. https://doi.org/10.1016/j.jad.2020.05.009

Xiao, X., Zhu, X., Fu, S., Hu, Y., Li, X., \& Xiao, J. (2020). Psychological impact of healthcare workers in China during COVID-19 pneumonia epidemic: a multi-center cross-sectional survey investigation. Journal of Affective Disorders, 274, 405-410. https://doi.org/10.1016/j.jad.2020.05.081

Zamarro, G., \& Prados, M. J. (2021). Gender differences in couples' division of childcare, work and mental health during COVID-19. Review of Economics of the Household, 19, 11-40. https://doi. org/10.1007/s11150-020-09534-7 